\title{
LINGUAGEM HUMANA: UMA ANÁLISE SOBRE A ESCRITA
}

\author{
Tamara Cristina Penha da Costa ${ }^{1}$ \\ Robervania de Lima Sá Silva² \\ Antonia Samara Sousa ${ }^{3}$ \\ Walnélia Benigno Magalhães Carrijo ${ }^{4}$
}

\section{INTRODUÇÃO}

A comunicação é um fator essencial para a sobrevivência dos indivíduos no ambiente social, ela sempre se fez presente em diferentes contextos na vida do homem. A milhões de anos atrás a humanidade, para satisfazer suas necessidades, precisou fazer uso da linguagem escrita, que provavelmente teve início por meio de desenhos feitos em paredes de cavernas seguidos da reprodução de alguns traços. Somente ao longo de muitos anos a escrita começou a evoluir em diferentes lugares do mundo e adquirir formas mais complexas e eficazes.

Assim, ela nasceu a partir das necessidades humanas para, posteriormente aliar-se ao desenvolvimento da sociedade e do comércio com o estabelecimento de trocas comerciais entre diferentes povos do mundo em que, para tanto, era necessário o registro das atividades que realizavam; com isso, a escrita passou por diferentes processos de transformação que proporcionaram melhorias para a vida das pessoas.

A história da escrita é dividida em vários momentos: primeiramente os objetos eram representados por meio de desenhos - sendo esta a escrita pictográfica- com o processo de evolução que ocorreu de forma natural nasce a escrita cuneiforme e posteriormente a ideográfica, na qual os símbolos passam a representar ideias ou conceitos, assim o desenho de um sol podia representar não apenas um símbolo como o astro, mas também a ideia de dia. A próxima etapa da evolução da escrita foi denominada de escrita fonética, em que os signos não estabelecem uma aproximação com o objeto, mas sim com os sons.

\footnotetext{
${ }^{1}$ Universidade do Estado do Pará - e-mail: tamaracristina390@gmail.com

${ }^{2}$ Universidade do Estado do Pará - e-mail: robervania.sa@bol.com.br

${ }^{3}$ Universidade do Estado do Pará - e-mail: antoniasamarasousa@gmail.com

${ }^{4}$ Universidade do Estado do Pará - e-mail:walnelia@yahoo.com.br
} 
Para desenvolvimento do presente trabalho fora realizada uma pesquisa bibliográfica por ela possuir um planejamento que se organiza em torno de materiais já elaborados. (GIL, 2008). Assim sendo, foi realizada uma análise com base nas pesquisas publicadas dos seguintes teóricos da área da história da linguagem escrita: Barbosa (1992), Bosi (1996), Cervo; Berviam e Da Silva, (2007), Geraldi (1997), Higounet (2003), Luria (1986), Marchushi (2000) e (2001), Rojo (2006), Saussure (2002) e Viana (2012), e Gil (2008). Todos os estudos realizados conduziram o processo da pesquisa e revelaram a importância da linguagem escrita para a humanidade desde o seu surgimento até o mundo contemporâneo, onde há uma variedade de linguagens e símbolos escritos que norteiam o convívio social, criando códigos linguísticos que incluem ou excluem aqueles que não tem acesso aos mesmos.

\section{LINGUAGEM HUMANA}

A linguagem, processo de comunicação humana é de suma importância para a convivência dos indivíduos no meio social, ela consiste em um conjunto de signos e símbolos utilizados para se comunicar, assim por meio dela ocorre a interação entre os membros de determinado grupo, seja por meio da linguagem falada ou escrita, linguagens de sinais, corporal etc. onde realiza-se a troca de ideias e informações, fatores que proporcionam o compartilhamento de experiências. Constituindo-se um recurso de fundamental importância em nossa vida.

Podemos afirmar que ela faz parte do ser humano, pois a partir de suas necessidades buscam relacionar-se e interagir com os outros na sociedade com intuito de alcançar seus objetivos, assim como adquirirem a capacidade de realizar mudanças. Logo, o sujeito é capaz de revelar-se por meio da linguagem. "Os sujeitos se constituem como tais, à medida que interagem com os outros. Sua consciência e seu conhecimento de mundo resulta como "produto" deste mesmo processo" (GERALDI, 1997, p. 06).

A comunicação desenvolvida pelos indivíduos no âmbito da sociedade deve-se a interação que estabelecem em determinado sistema que é a língua. Para Saussure (2002) ela é o produto do meio social, responsável pelo desempenho dos sujeitos no ambiente em que atuam, ou seja, é um sistema de valores, fato social que resulta da coletividade e da capacidade de relacionar-se com os outros. É 
importante a relação que estabelecem com os demais, pois a convivência em determinados grupos não depende apenas do próprio sujeito, pois a formação do conhecimento se dá a partir das experiências que estabelecem com outras pessoas.

Dessa forma, a linguagem abrange diversas modalidades, cada uma com sua utilidade, sendo a escrita uma das mais importantes, pois ela faz parte da vida do homem desde o momento em que proporcionou a comunicação com as pessoas levando os mesmos a conviverem em grupos a fim de facilitar a luta pela sobrevivência no meio que habitavam, a partir do avanço desta que ocorreu com o desenvolvimento da sociedade e do homem ela desempenhou, e ainda continua desempenhando, papel fundamental na construção do homem enquanto ser social.

A escrita constitui um recurso voltado para o registro das atividades do indivíduo, é o meio pelo qual expressam suas opiniões em relação a determinado assunto, não se limitando somente a representação do alfabeto e das palavras ela passa a ser produzida durante o processo de interação, formando desde frases complexas até textos abstratos, que, por sua vez, devem obedecer a regras, normas, ou seja, não é possível escrever de qualquer forma, pois existem regras preestabelecidas que variam de acordo com a ocasião em que o sujeito esteja vivenciando. Assim, a escrita estabelece a representação visual da linguagem por meio dos signos gráficos. Como explica Viana (2012, p. 03):

Conforme o dicionário de linguística de Dubois "Escrita é uma representação da linguagem falada por meio dos signos gráficos". Em um aspecto mais técnico corresponde ao processo de transformação das idéias no plano mental para a representação gráfica, sob a condução de um plano de escrita e suas exigências de explicitação e organização de idéias.

As formas de comunicação humana, como vimos anteriormente, sempre se fizeram presentes na vida das pessoas abrangendo diversas modalidades. No princípio, o homem primitivo fazia uso das expressões corporais: gestos e determinadas posturas, a fim de estabelecer comunicação com os demais, depois de muito tempo aprenderam a se relacionar por meio da imitação de gestos com repetição de alguns sons, criando assim uma linguagem simples que foi evoluindo com o tempo e de acordo com suas necessidades.

É importante ressaltar que, apesar de haverem muitas pesquisas na área, o estudo sobre a origem da linguagem ainda precisa de análises mais aprofundadas, uma vez que muitos dados a esse respeito circundam em torno de hipóteses, por 
isso, dizemos que é possível que ela tenha se originado a partir da imitação de sons acompanhado de gestos, bem como das necessidades do homem como a sede, fome, abrigo, reprodução, dentre outros, fazendo com que o mesmo se agrupasse com os demais a fim de buscar condições propícias que garantissem sua sobrevivência.

\section{ESCRITA: BREVES CONSIDERAÇÕES}

Para transmitir seus conhecimentos e como meio de sobrevivência a humanidade sempre dependeu da comunicação, mas nem sempre houve sistemas organizados como atualmente.

O aparecimento das primeiras manifestações de escrita no mundo teve início por meio de uma extensa jornada evolutiva que vem desde o homem préhistórico. Sua aparição se deu em diferentes lugares e de diversas formas. Assim, a escrita se tornou a principal ferramenta de comunicação e divulgação de ideias do homem.

As primeiras formas de escrita surgiram no período paleolítico sendo desenvolvidas possivelmente pelo homem primitivo. Constituíam gravações em pequenos objetos e pinturas que foram encontradas principalmente em paredes de cavernas na qual habitavam. Elas eram bem simples e utilizavam poucos signos que eram feitos em superfícies de pedras, argila ou madeira. Tais pinturas também foram denominadas de pinturas "rupestres", ao longo dos anos está escrita foi evoluindo dando origem a formas mais complexas. Ela representavam o modo de vida do homem primitivo e foi fundamental para o registro de atividades do homem naquela época.

Neste período histórico surge a necessidade do ser humano registrar os acontecimentos de seu cotidiano por meio de desenhos que pudessem representalo, assim fizeram uso das paredes de cavernas e até mesmo outros objetos como visto acima, também é importante ressaltar que estas imagens elaboradas traziam uma significância para quem as produziam. Apesar de sua grande importância para a história da humanidade e devido ser responsável pelos primeiros registros escritos, não é caracterizada como um sistema de escrita. 
O surgimento da escrita encontra-se relacionado com a evolução das primeiras civilizações urbanas na região entre os rios Tigres e Eufrates, na Mesopotâmia, cidade de Ur, com sua eficácia e melhoria para a vida daquela população se tornou objeto de necessidade para o homem exprimir-se e comunicase, sofrendo modificações que não se deram de um momento para outro, pois é um processo que ocorreu e continua ocorrendo de forma natural.

Ressalta-se que apesar de sua importância para a sociedade não existe relato de seus criadores, apenas de época, povos e locais em que surgiram os primeiros registros, chamados cuneiformes, desenvolvido pelos sumérios na Mesopotâmia, seu aparecimento se deu por volta do ano 4.000 a.C., sendo que muitos historiadores como Barbosa (1991) determina seu aparecimento no ano 6.000 a.C., afirmando que "o primeiro registro que se conhece é uma pequena lápide, encontrada nos alicerces de um templo em Al Ubaid. O construtor do templo escreveu nela o nome do seu rei. Esse rei pertenceu a dinastia entre 3.150 e 3000 a.C."

A escrita cuneiforme é um tipo de grafia representado pela mistura de caracteres e símbolos que se transformaram em sílabas e letras e foram originadas por meio das escritas rupestres, como dito anteriormente, consistem em desenhos feitos em rochas representando o modo de vida do homem primitivo. "A escrita cuneiforme é herdada dos pictogramas e das pinturas rupestres, que, originalmente, registravam e representavam objetos, ações e cenas de grupos humanos". (ROJO, 2006, p. 12).

Sua utilização esteve relacionada com a contabilidade e administração, bem como registro de bens, marcas de propriedade, cálculos e transações comerciais, onde as informações eram registradas em tabletes de argila com estiletes. Devido a resistência desse material, é possível se ter acesso a vários textos desta época que se mantiveram conservados ao longo de todos esses anos.

A escrita foi inventada e transformada por povos da antiguidade, tendo ela nascido a partir das necessidades que estavam diretamente relacionadas ao poder econômico de algumas comunidades e povos que comercializavam produtos e que precisavam expandir e estabelecer negócios com outros povos. Estes foram os principais fatores responsáveis pelos primeiros registros de escrita, isto é, foi mediante as precisões de controle administrativo financeiro que a escrita foi se tornando mais elaborada. 
No momento em que alguém teve que explicar para um estranho o que significavam aqueles desenhos, ele se pôs, de certo modo, a lê-los, por exemplo, contando uma história que os desenhos representavam. Nesse momento, o desenho deixou de ser uma simples figura e passou a ser uma representação da linguagem e, por tanto, uma escrita. A técnica de representação da linguagem estava descoberta. (CAGLIARI, 1987, p. 165)

Assim, foi por meio da leitura que a escrita nasceu e pode ser definida como a representação gráfica da linguagem que por sua vez propicia a comunicação. Com isso, a escrita passou a ser desenvolvida mais rapidamente conforme alguém passou a ler e interpreta-la.

Por meio dela tornou-se possível a criação de outros sistemas de escrita por outros povos, aperfeiçoando e adaptando os símbolos, dando origem a sua própria forma de escrita. Com isso, as escritas foram se desenvolvendo conforme o homem necessitava de forma que suprissem suas atividades diárias, dando origem a outras mais elaboradas e completas como a escrita ideográfica que é caracterizado pela escrita de desenhos chamados de ideograma. Com o passar dos anos perdeu alguns traços da figura e se tornou uma simples escrita. "cada signo representava um objeto (pictograma ou ideograma). A escrita ideográfica exige milhares de signos e, por isso, um longuíssimo aprendizado" (ROJO, 2006, p. 14).

Com o passar dos anos as formas de comunicação escrita não apenas evoluíram, mas também permitiram que outras surgissem. Por isso, destaca-se posteriormente o surgimento do sistema de escrita alfabética por volta do ano 2000 a.C. como representação da língua e tinha como objetivo sua utilização pelos escravos semíticos no Egito, este sistema de escrita é de fundamental importância, uma vez que propiciou o surgimento da maioria dos alfabetos, segundo Higounet, "o alfabeto pode ser definido como um sistema de sinais que exprimem os sons elementares da linguagem" (2003, p. 59). A palavra alfabeto vem do grego "alfa" e "beta" e do latim alphabetum em que a junção das duas letras do alfabeto grego "alfa" e "beta" resultou na formação de "alfabeto".

Esse sistema de escrita com suas técnicas e instrumentos, configura outra redefinição no processo de comunicação escrita que não consiste primeiramente na invenção de uma série de signos gráficos, mas na decomposição da palavra em sons simples, em que cada qual é representado por um só signo, ou seja "o sistema silábico onde cada signo representa um som decomposto (fonemas 
e não mais silabas). Esses signos podem se combinar para representar sons diferentes" (ROJO, 2006, p. 15).

Sendo assim, essa forma de escrita se deu em decorrência do aprimoramento das anteriores, pictografia, cuneiforme e ideografia, conforme demostrado anteriormente consistem em símbolos que foram evoluindo, de início com a utilização de desenhos representando sons da fala e posteriormente letras do alfabeto. Apresentando assim uma mudança em relação a ideográfica, pois ocasionou a redução de caracteres na mudança de ideogramas para silabas e também o significado passou a ser construído a partir dos sons das palavras e não pelas ideias.

Portanto, as silabas também não foram suficientes para o sistema de escrita por apresentarem algumas redundâncias. Observe: PA, BA, TA, LA, etc. fazendo-se necessário uma nova organização com a criação de novos caracteres bem como, A, B, C, T, J, etc. Com essa reorganização a escrita passa por uma mudança do sistema ideográfico para o fonográfico.

Segundo demostra Cagliari:

O a era a representação da cabeça de um boi na escrita egípcia. Em grego, o alfa se escreve _. O $b$ era a representação de uma casa egípcia. O $d$ era a figura de uma porta. $\mathrm{O} m$ era 0 desenho das ondas da água. $O n$ era 0 desenho de uma cobra. $O$ era a figura de um olho. $O x$ representava 0 peixe, e assim por diante. (CAGLIARI, p. 108 apud GOMES, s/d).

Dessa maneira, a linguagem que utilizamos para nos comunicar hoje, nasceu no momento em que o homem precisou de formas mais eficazes para garantir sua sobrevivência, este procedimento não ocorreu de repente, de um momento para outro, mas a milhões de anos atrás e com o passar do tempo foi sendo modificada e aperfeiçoada dando origem a outras formas mais evoluídas.

É importante lembrar que este fato tornou-se possível devido as transformações que ocorrem na linguagem fazendo com que ela não permanecesse estacionada, ou seja, a todo momento ela está sujeita a mudanças devido a ação do homem. (ROJO, 2006, p. 17):

[...] num primeiro momento, ela era simples: representava os objetos, as imagens das coisas e dos seres. Foi se tornando mais e mais abstrata, nos ideogramas, representando idéias por meio de combinações de pictogramas. Posteriormente, esses mesmos pictogramas e ideogramas 
que representavam imagens de coisas passaram a representar os sons das palavras que designavam essas mesmas coisas.

Dessa forma, como podemos notar anteriormente a escrita percorreu um longo processo de evolução, onde destaca-se a escrita rupestre, cuneiforme, ideográfica e alfabética surgidas em diferentes contextos e lugares, sendo que todas exerceram e ainda continuam exercendo papel fundamental na vida do homem mesmo em diferentes momentos da história. Percebe-se, dessa forma, como as influências da relação social do homem com os outros e as dificuldades que enfrentaram para sobreviver contribuíram para o aperfeiçoamento da comunicação escrita fator essencial para o desenvolvimento da sociedade.

\footnotetext{
Podemos, portanto, definir a escrita, de maneira mais geral, como representação visual da linguagem por um sistema de signos gráficos adotados convencionalmente por uma comunidade. Ao longo de sua história, as escritas utilizaram suportes muito variados: da pedra à terra seca ou cozida aos muros urbanos, do papiro ao papel, do filme à tela do computador ou da tv. (ROJO, 2006, p. 13).
}

O homem, assim como a escrita, passou por um processo extenso de desenvolvimento, pois a medida que ele evoluía e a sociedade se transformava, também era necessário a utilização de um código que suprisse a demanda do contexto social da época, com isso fizeram uso de diversas técnicas de escrita cada vez mais desenvolvidas.

\section{A IMPORTÂNCIA DA LINGUAGEM NA VIDA DAS PESSOAS}

A linguagem constitui um dos recursos mais importantes na vida do ser humano, pois é por meio dela que os indivíduos são capazes realizarem suas atividades no dia a dia, mas para isso também é preciso que haja interação social por meio da comunicação com os membros da sociedade, este fato passa a ocasionar uma relação de dependência de uma pessoa para com as outras para viverem em sociedade. Por meio dela, as pessoas são capazes de realizarem diversas atividades, assim como construir e transformar o mundo, dando oportunidade para o indivíduo reproduzir o que sente, expressar sentimentos e seu pensamento. 
Podemos afirmar que a mesma é um elemento que faz parte da natureza do ser humano, uma vez que ela representa uma importante ferramenta de comunicação sendo utilizada de acordo com os interesses que cada indivíduo possui afim de realizar seus objetivos, e com isto são levados a interagirem com o outro.

Sem a existência da mesma se tornaria difícil a sobrevivência dos sujeitos no meio social, pois precisam interagir com os outros, com o mundo e consigo mesmo, construindo relações sociais. Assim, ela também é responsável pela transmissão de valores culturais, visto que é no mundo da cultura que ocorre a interação entre as pessoas construindo nossa identidade pessoal e social. Através dela, o homem tem a possibilidade de tornar-se sujeito, capaz de construir sua própria trajetória, tornando assim, um ser histórico e social.

A linguagem propicia a formação de valores culturais, onde Bosi (1996) conceitua cultura como o conjunto de práticas, de técnicas, de símbolos e de valores na qual devem ser transmitidos as futuras gerações como forma de garantir a convivência social. Porém, para que exista cultura faz-se necessário que antes dela possa existir também uma consciência coletiva que, por meio da vida cotidiana, seja capaz de elaborar futuros planos para a comunidade. Esta definição favorece à cultura um significado mais próximo do ato de educar. Dessa forma o termo cultura se relacionaria a todo ensinamento que um povo transmite para seus descendentes como forma de garantir sua sobrevivência.

Assim, a linguagem desempenha papel fundamental no processo de interação social, contribuindo para a construção do sujeito enquanto ser histórico e social. Dessa forma, ela não se resume apenas a comunicação ou expressão do pensamento do indivíduo, mas também ao ato interlocutivo ente os sujeitos como já mencionado anteriormente. Com isso a linguagem é caracterizada como um produto social de lugar, negociação de sentidos, ideologias e conflitos.

O processo de comunicação concebido pela linguagem é um método no qual as pessoas estabelecem relações mutuas, compartilhando experiências, bem como transmitir e receber conhecimentos. Assim, conclui-se que a linguagem é a possibilidade de interação comunicativa buscando a produção e construção de significados, de sentidos, enfim, de elaboração de conhecimento.

\section{CONCLUSÃO}


A linguagem humana perpassou e ainda continua perpassando por um longo processo evolutivo acompanhado pelas mudanças que ocorrem na sociedade. Há milhões de anos atrás ela começou a fazer parte da vida do homem servindo de instrumento muito preciso para a realização de suas atividades e para que pudessem garantir sua sobrevivência precisaram se unir por meio de um grupo social.

O sistema de escrita sofreu diversas mudanças ao longo do tempo acompanhadas juntamente das transformações que ocorriam na sociedade. Assim, em diferentes lugares do mundo ela se desenvolveu de forma distinta, pois com sua criatividade o homem utilizou de diversos instrumentos afim de aperfeiçoa-la. Por meio da linguagem nasceu as múltiplas possibilidades de comunicação, que se tornou possível devido a interação entre os indivíduos, a possibilidade de compartilhar conhecimentos e experiências de vida.

Percebe-se, dessa forma que a linguagem humana constitui um recurso de fundamental importância para a comunicação do indivíduo, sendo que por meio dela tem-se a capacidade de transformar, construir e destruir coisas. Ela é modificada pela ação praticada pelos indivíduos, que em diferentes épocas se manifesta de maneiras distintas.

A escrita constitui hoje uma ferramenta muito importante na vida do ser humano, uma vez que se faz presente de maneira tão significativa que seria impossível imaginar a existência da humanidade sem a mesma, ocorrendo dessa forma uma relação de dependência do homem para com a linguagem escrita.

\section{REFERÊNCIAS}

AMADO; BERVIAM E DA SILVA. Metodologia cientifica. $6^{\circ}$ ed. São Paulo: Pearson Prentice Hall, 2007.

BARBOSA, José Juvêncio. Alfabetização e Leitura. São Paulo: Cortez, 1991. BOSI, Alfredo. Dialética da colonização. São Paulo. Companhia das Letras, 1996. GERALDI, João Wanderley. Portos e passagem. São Paulo: Martins Fontes, 1997. GIL, Antonio Carlos. Como elaborar um projeto de pesquisa. 4 ed. São Paulo: Atlas, 2008. 
GOMES, Eduardo de Castro. A escrita na História da humanidade. S/D. Disponível em:http://dialogica.ufam.edu.br/PDF/no3/Eduardo_Aspectos_da_escrita_na_Historia da_humanidade.pdf Acesso em: 22 Junho 2015.

HIGOUNET, Charles. História concisa da escrita. 10ª edição - São Paulo: Parábola Editorial, 2003.

MARCUSHI, Luiz Antonio. Da fala para a escrita. São Paulo: Cortez, 2001.

ROJO, Roxane. As relações entre fala e escrita: mitos e perspectivas-caderno do professor. Belo Horizonte: Ceale, 2006.

SAUSSURE, Ferdinand d. Curso de Linguística Geral. Org. de Charles Baley Abert Sechehay e com colaboração de Albert Riedlinger. Trad. Antonio Cheline, José Paulo Paes e Izidoro Bleikstein. 24 ed. São Paulo: Pensamento-Cutrix, 2002.

VIANA, Neilane de Souza. A linguagem escrita na era da tecnologia: investigando a informalidade nas comunicações on line. Revista vozes dos vales da UFVJM: Publicações Acadêmicas-MG-Brasil-№ 02-Ano I- 10/2012. Reg: 120.2.095-2011-PROEXC/ UFVJM- ISSN: 2238-6424. 